Andrews University

Digital Commons @ Andrews University

Faculty Publications

$9-1-2005$

\title{
The Implications of Conjunctive and Disjunctive Forgiveness for Sexual Abuse
}

Herbert W. Helm

Andrews University, helmh@andrews.edu

Jonathan R. Cook

John M. Berecz

Follow this and additional works at: https://digitalcommons.andrews.edu/pubs

Part of the Counseling Psychology Commons

\section{Recommended Citation}

Helm, Herbert W.; Cook, Jonathan R.; and Berecz, John M., "The Implications of Conjunctive and Disjunctive Forgiveness for Sexual Abuse" (2005). Faculty Publications. 2174.

https://digitalcommons.andrews.edu/pubs/2174

This Article is brought to you for free and open access by Digital Commons @ Andrews University. It has been accepted for inclusion in Faculty Publications by an authorized administrator of Digital Commons @ Andrews University. For more information, please contact repository@andrews.edu. 


\title{
The Implications of Conjunctive and Disjunctive Forgiveness for Sexual Abuse
}

\author{
Herbert W. Helm Jr., ${ }^{1}$ Jonathan R. Cook, and John M. Berecz
}

This article examines the relationship between forgiveness styles (conjunctive and disjunctive models) and sexual abuse. Surveys from 114 university students were analyzed for differences between non-sexually abused and sexually abused subjects on a number of psychological and physical well-being variables. A number of differences were found including higher levels of reported verbal and physical abuse for the sexually abused subjects. Only one sexually abused subject was found that fit the pattern of conjunctive forgiveness (one of reconciliation) towards the offender. The majority of sexually abused subjects preferred to keep their distance from the abuser, regardless of the extent to which the abuser had been forgiven. The results suggest that reconciliation withinforgiveness may not be an appropriate goal for all subjects.

KEY WORDS: sexual abuse; forgiveness; conjunctive; disjunctive.

The purpose of this study was to examine how varying forgiveness styles are related to the issue of sexual abuse. Sexual abuse is a global concern that affects men and women throughout the world (Oaksford \& Frude, 2001; Madu \& Peltzer, 2001; Feehan, Nada-Raja, Martin, \& Langley, 2001; Romero, Wyatt, Loeb, Carmona, \& Solis, 1999). Forgiveness, traditionally a topic of theological discussion, has usually been viewed as equivalent to reconciliation. More recently, it has been argued that there are alternative methods, or styles, of forgiveness that are equally valid, particularly for victims of abuse (Berecz, 2001).

Victims of sexual abuse can be found among virtually every racial, gender, religious, and socioeconomic subgroup (Wyatt, Loeb, Solis, Carmona, \& Romero, 1999). However, it has only been within the past two decades that sexual abuse has received significant public attention and academic study (Haugaard, 2000).

\footnotetext{
${ }^{1}$ Address correspondence to Herbert W. Helm Jr., PhD., Department of Behavioral Science, Nethery Hall Room 123, Andrews University, Berrien Springs, Michigan 49104; e-mail: helmh@andrews.edu.
} 
Despite increasing awareness and scholarly research, a standard definition of sexual abuse has yet to be agreed upon by lawmakers, clinicians, and researchers. Sexual abuse is frequently defined as including the following elements: coercive and/or manipulative sexual contact, a relationship between the abuser and the victim that is characterized by the abuser's relative power over the victim, and, in cases of child sexual abuse, a victim that is legally considered to be a child during the time period in which the abuse took place. Verbal comments and non-contact sexual activity are less frequently included as definitional elements of sexual abuse (Paolucci, Genuis, \& Violato, 2001; Rind, Tromovitch, \& Bauserman, 1998).

Reports on the prevalence of sexual abuse show considerable variance. Various studies indicate $12 \%$ to $54 \%$ of girls and $3 \%$ to $16 \%$ of boys report that they have been sexually abused (Finkelhor, Hotaling, Lewis, \& Smith, 1990; Molnar, Buka, \& Kessler, 2001; Holmes \& Slap, 1998). In the 1970's a study was conducted gathering data from a population of college students and found that $19 \%$ of the women and $8.6 \%$ of the men reported being sexually victimized as children (Finkelhor, 1979). Almost a decade later, in the 1980's, researchers found that 20\% of women and 7\% of men indicated that they had been sexually abused (Siegel, Sorenson, Golding, Burnam, \& Stein,1987). These earlier findings are fairly consistent with a more recent study in which American and Canadian sexual abuse literature from the past 25 years was systematically reviewed. Based on analysis of these studies the researchers estimated that the prevalence rate of child sexual abuse is 23\% for girls and 9\% for boys (Goery \& Leslie, 1997). While there is considerable variance in the body of literature concerning the general prevalence of sexual abuse, most studies indicate that the prevalence rate for women is two to three times higher than for men. However, some researchers (Boney-McCoy \& Finkelhor, 1995) argue that the prevalence of sexual abuse among men is underestimated because they are stigmatized by society for any type of same-sex behavior and therefore do not report it as frequently during sexual abuse studies.

There has been increasing evidence linking sexual abuse to a variety of negative physical and emotional consequences both during the time of abuse and later in the victim's life. Studies in which sexually abused and non-sexually abused children were compared have shown statistically significant correlations between being a victim of sexual abuse and engaging in self-harmful behavior, inappropriate sexual behavior, developing post-traumatic stress disorder, and having low selfesteem (Beitchman, Zucker, Hood, daCosta, \& Akman, 1991; Conte \& Schuerman, 1987; Kendall-Tackett, Williams, \& Finkelhor, 1993).

Sexually abused individuals develop numerous problems later in life as well. Medical problems such as chronic pain (Finestone, Stenn, Davies, Stalker, Fry, \& Koumanis, 2000) and increased gastrointestinal problems (Berkowitz, 1998) have been reported to plague sexual abuse victims in adulthood. Wyatt, Guthrie, \& Notgrass (1992) found that victims of sexual abuse have more unintended pregnancies and abortions. Numerous studies have detailed the correlation between 
childhood sexual abuse and engaging in risky sexual behaviors such as low usage of condoms, impulsive sex, and prostitution as an adult (Allers, Benjack, White, \& Rousy, 1993; Browne \& Finkelhor, 1986; Thompson, Potter, Sanderson, \& Maibach, 1997).

Sexual abuse has also been shown to negatively impact an individual's ability to engage in normal and healthy interpersonal relationships with others. A study (Jackson, Calhoun, Amick, Maddever, \& Habif, 1990) concerning college women and sexual abuse found that victims of incest had more trouble in dating relationships, achieving sexual satisfaction, and had higher levels of depression. Mayall and Gold (1995) documented a correlation between sexual abuse and a later-life tendency to have casual or impulsive sex with a greater number of partners. Finklehor, Hotaling, Lewis, and Smith (1989) found statistically significant correlations among women who had been sexually abused as children and a tendency to become pregnant before age 19 and have increased rates of separation and/or divorce.

Another negative effect of sexual abuse is an increased risk of revictimization in adulthood (Chu, 1992; Gidycz, Coble, Latham, \& Layman, 1993). Messman and Long (1996) conducted a study in which they found the single strongest predictor of adult sexual revictimization was childhood sexual abuse. Childhood sexual abuse has also been associated with increased usage and abuse of alcohol and illicit substances (Jantzen, Ball, Leventhal, \& Schottenfeld, 1998; Wingood $\&$ DiClemente, 1997). Several studies indicate a strong correlation between childhood sexual abuse and increased substance abuse, even after controlling variables such parental divorce, parental substance abuse, and physical and emotional abuse (Kendler et al., 2000; Vogeltanz-Holm, 2002).

As with the research on overall prevalence of sexual abuse, there are conflicting research studies on the relationship between the abuser and victim. Information from the Child Custody Protection Act (National Right to Life, 1999) indicated that $80 \%$ of victims of sexual abuse are abused by family members and that $19 \%$ are abused by other trusted adults. Research has shown that nearly a quarter of men and women who are victims of sexual abuse were victims of incest (Finkelhor, 1979). Conversely, Kenny and McEachern (2000) conducted a study in which $18 \%$ of the women indicated that they had been sexually abused. The majority of these women indicated that they had been abused by non-family members such as neighbors, acquaintances, or friends of the family. Twenty-one percent of the women indicated that their abuser had been a stranger.

The scholarly literature on the topic of forgiveness is not as prolific as that on sexual abuse. Traditionally, forgiveness has been seen as a topic within the domain of theology and therefore unamenable to scientific study. However, there has been a recent paradigm shift among psychologists who are now interested in the potential psychological benefits resulting from the forgiveness process. Psychological literature generally equates forgiveness with some form of reconciliation, a view 
that has roots in traditional Judeo-Christian religious belief. In some instances, forgiveness is seen as pardoning the offender from his or her transgressions in addition to reconciling. Freedman and Enright (1996) argue that forgiveness involves letting go of resentment and showing compassion to the offender, but does not necessitate that the victim retain an ongoing relationship with the offender.

Several psychologists refute the idea of reconciliatory forgiveness because it often carries the connotation that it is necessary to resolve past conflicts and preserve the relationship between two individuals in order to forgive. Konstam, Marx, Schurer, Harrington, Lombardo, and Deveney (2000) maintain that reconciliation between the victim and the offender is not a necessary condition for forgiveness to occur. Furthermore, they argue that reconciliatory forgiveness may not be feasible if the offender does not recognize his transgressions or is unwilling to make amends for them.

Literature pertinent to both sexual abuse and forgiveness indicates that there are a number of positive benefits resulting from a victim's choice to forgive their abuser. Hebel and Enright (1993) found a correlation between a victim's ability to forgive a perpetrator and facilitated psychological healing and a reduction in negative self-referenced feelings. Another study (Freedman \& Enright, 1996) labeled forgiveness as an intervention goal for victims of incest. Victims who were able to forgive their abusers experienced significant psychological benefits including reduced levels of depression and anxiety as well as raising the individual's self-esteem. Several researchers (Enright, 2000; Berecz, 2001) maintain that in some instances it is not desirable for the victim to preserve a relationship with the transgressor, particularly when maintaining a relationship with the abuser can potentially be physically and psychologically dangerous for the victim.

Berecz (2001) describes two main types of forgiveness; conjunctive and disjunctive. Conjunctive forgiveness includes reconciliation between two parties. Berecz argues that reconciliation is frequently not possible and sometimes undesirable. In cases of abuse it is necessary for a disconnection to occur between the abuser and the victim in order for healing to take place. He defines disjunctive forgiveness as the process in which a victim decides to forgive his transgressor and show compassion but chooses to remain emotionally and physically distant from the offender. Disjunctive forgiveness is not dependent upon feelings of remorse or empathy from the perpetrator. Disjunctive mutual forgiveness occurs when an individual and a perpetrator both forgive one another but choose to keep emotional and physical distance from one another. Berecz argues that disjunctive forgiveness is not necessarily a pardon. He illustrates this through saying, "one can forgive one's little daughter for messing up the living room and insist that she clean up the clutter" (pg 18). This is particularly relevant to victims of sexual abuse who may be in the process of forgiving their abuser but still have a strong desire that the abuser be held legally responsible for his or her actions. Berecz acknowledges that disjunctive forgiveness does not allow for the emotional closeness that can 
potentially be regained through reconciliation but it does allow a victim to leave bitterness behind. As such, disjunctive forgiveness is an important tool in helping victims of sexual abuse to begin the healing process without forcing them to create an uncomfortable and often unrealistic reconciliation with their abuser.

As noted earlier, the purpose of this paper is to examine the relationship between sexual abuse and forgiveness styles. In particular, this study looks at conjunctive and disjunctive models of forgiveness as they relate to sexual abuse.

\section{METHOD}

\section{Participants}

Subjects were students attending Andrews University, a Seventh-day Adventist sponsored school. There were 922 surveys distributed in the three residence halls (one for females and two for males) and 114 of the surveys were returned, this is a return rate of $12.4 \%$. Of the 114 completed surveys, 26 were male $(22.8 \%)$ and 88 were female $(77.2 \%)$. In order to avoid the issue of parental consent, individuals under the age of 18 were asked not to participate in the study. Subjects received a note of thanks in the survey packet for participating in the survey, and it was noted that their participation was entirely voluntary. The cover letter asked them to answer with their actual feelings as opposed to how they thought they should feel.

Of subjects who returned the survey, 91 indicated that they had not been sexually abused $(79.8 \%)$, and 23 subjects reported that they had been sexually abused (20.2\%). In the non-sexually abused group, $74.7 \%$ were female $(N=68)$ and $25.3 \%$ were male $(N=23)$. In the sexually abused group, $87 \%$ were female $(N=20)$ and $13 \%$ were male $(N=3)$. In the non-sexually abused group, $60.4 \%$ were Caucasian $(N=55), 14.3 \%$ were African American $(N=13), 7.7 \%$ were Hispanic $(N=7), 7.7 \%$ were Asian/Pacific Islander $(N=7), 8.8 \%$ were Other $(N=8)$, and 1 was missing. In the sexually abused group, $39.1 \%$ were Caucasian $(N=9), 8.7 \%$ were African American $(N=2), 8.7 \%$ were Hispanic $(N=2)$, $17.4 \%$ were Asian/Pacific Islander $(N=4), 21.7 \%$ were Other $(N=5)$, and 1 was missing. Both groups came from fairly intact families, for those in the nonsexually abused group, $84.6 \%$ came from families in which they were raised by both parents living in the same home, while for the sexually abused group it was $73.9 \%$.

\section{Instrument}

The survey consisted of 55 questions, however, a number of the questions had multiple answering options. The two biggest influences in its design were the 
Michigan Criminal Sexual Code Statute (University of Michigan, Sexual Assault Prevention \& Awareness Center, n.d.) and the Enright Attitude Scale (Subkoviak, Enright, Wu, \& Gassin, 1995). The first section of the survey was completed by both the non-sexually and sexually abused subjects and consisted of questions dealing with demographics, family structure, physical and emotional health, and whether various types of abuse had occurred to them. The second section was only completed by those reporting sexual abuse and consisted of questions dealing with types of sexual abuse, forgiveness, and circumstances, thoughts, and emotions concerning the abuse and the abuser.

\section{RESULTS}

\section{A Comparison of Non-sexually and Sexually Abused Subjects}

In comparing the non-sexually abused subjects to the sexually abused subjects a number of interesting results were found. In terms of physical health, $63.8 \%$ of the non-sexually abused subjects reported 'above average' to 'excellent' overall physical health, whereas, only $39.1 \%$ of the sexually abused group reported the same categories. In comparing the number of doctor visits, the sexually abused subjects reported a greater frequency, with $34.8 \%$ reporting in categories of 'several times per year' to 'more than one per week,' compared to $21 \%$ of the non-sexually abused subjects.

In terms of mental health, $55.5 \%$ of the non-sexually abused subjects reported 'above average' to 'excellent' emotional health, whereas, only $22.7 \%$ of the sexually abused group reported the same categories. For 'below average' emotional health, it was 3.3\% for the non-sexually abused subjects, verses $18.2 \%$ for the sexually abused subjects. This lowered mental health for the sexually abused subjects may be supported by these same subjects indicating that $82.6 \%$ of them had seen a psychologist, psychiatrist, or counselor, whereas, only $31.9 \%$ of the non-sexually abused subjects reported the same.

Both groups were asked on whether they had ever been physically, verbally, or sexually abused. For those in the non-sexually abused group, only 19.8\% reported verbal abuse, whereas, $72.7 \%$ in the sexually abused group also reported verbal abuse. In a similar vein, only $3.3 \%$ of those in the non-sexually abused group reported physical abuse, whereas, $39.1 \%$ of the sexually abused group also reported physical abuse.

\section{Characteristics of the Abused and Abusers}

While there was considerable age variation for when the sexual abuse began (an age range of 5-35), for $65.2 \%$ the sexual abuse began between the ages 
of 5 through 9. The majority of the abuse took place in the home, though the 'neighborhood' and 'other' were the next most frequently cited categories. A single abuser was reported by $60.9 \%$ of the subjects, while $39.1 \%$ reported more than one abuser, with a range from 2-5. No discernable pattern was noted for the age of the abusers.

Subjects were asked a number of questions about their abuser. If there was more than one, they were asked to fill out the questions in regards to the primary sexual abuser, this was defined as the one who committed a majority of the abuse. From here on, the results will be in regards to the primary sexual abuser.

The vast majority of abusers were male (87\%), a finding that is consistent across nearly all studies of sexual abuse (Wakefield, Rogers, \& Underwager, 1990). When examining the relationship between the abuser and the victim it was found that the most frequently cited abusers were uncles and cousins. Of the twenty-three individuals who were sexually abused only 10 of them $(45 \%)$ indicated that they had reported their abuse to at least one parent. Twelve indicated that they had not reported the abuse to anyone and one did not respond. Of those who did report the sexual abuse the most common result was that it remained a family or personal secret, with 7 subjects reporting this. Only one subject reported the sexual abuse to the police. None of the victims indicated that any of the sexual abusers had been prosecuted.

Of those reporting various types of sexual abuse, $80 \%$ reported touching, $80 \%$ reported fondling/rubbing, $70 \%$ reported 'other' abuse, $60 \%$ reported oralgenital contact, $22.2 \%$ reported oral-genital to climax, $21.2 \%$ reported genitalgenital without penetration, and $16.7 \%$ reported genital-genital with penetration. Of course, the subject could report more than one category.

\section{Emotions, Thoughts, and Behaviors About the Abuser}

A number of emotions, thoughts, and behaviors about and towards the abuser were assessed, both during the period of abuse, and at the time of the survey. Questions were asked on a Likert scale and ranged from 'not at all' $(0)$ to 'extremely' (4). Therefore, the higher the mean number the more of that quality or domain was being experienced.

On the emotional questions, five questions showed a statistically significant difference, with a decrease between the time of the abuse and the time of the survey. The decrease was on items dealing with feeling helpless (.003), ashamed (.001), guilty (.004), kind toward the abuser (.029), and affectionate towards the abuser (.007). Those items which had a mean of less than 1 (indicating being very low on this emotion) at both time periods included: happy, good, special, loved, excited, warm toward the abuser, positive toward the abuser, and caring towards the abuser. Those items which showed some mean change (though not statistically significant) toward the abuser included: resentful (1.62 during, 2.05 current), angry (1.76 
during, 2.05 current), bitter (1.55 then, 1.80 current), and hostile (1.24 then, 1.67 current). Those emotions which were seen as high, a mean of two or greater, for both time periods included being resentful, angry, and disgusted toward the abuser.

On the 'thought' or 'think about' questions, two showed a statistically significant difference, with both increasing over time: thought the abuser was immoral (.003) and thought they were corrupt (.016). Those items which had a mean of less than 1 (indicating being very low on this thought) at both time periods included thinking the abuser was worthy of respect, loving, good, nice, and caring. Thinking the abuser was horrible was moderately high at both time periods (1.52 then, 1.90 current). Thinking the abuser was a bad person was quite high (a mean of two or greater) for both time periods.

On the behavioral questions, five showed a statistically significant difference, with two decreasing and three increasing. Those items with a statistical increase were ignored the abuser (.002), don't/wouldn't speak to the abuser (.002), and stay away from the abuser (.047). Those items showing a statistical decrease were showed friendship to the abuser (.003), and had/have a good relationship with the abuser (.033). Those items which had a mean of less than 1 (indicating being very low on this behavior) at both time periods included helped the abuser and aided the abuser when they were in trouble. Items which were moderately high at both time periods were: I avoided the abuser ( 1.58 then, 2.32 current), stayed away from the abuser ( 1.50 then, 2.55 current) and considerate to the abuser (1.65 then, 1.15 current).

\section{Forgiveness}

Many of the forgiveness questions were on a 5 point Likert scale, with most questions being an option between what it was like and perceptions of what it will be like (since it is assumed that not all subjects have gone through or completed the forgiveness process). When asked about the process of forgiving the abuser, $86.4 \%$ of those who responded, indicated that it came from (or would come from) a mostly individual or personal process (a 1 on the Likert scale). The remainder gave it a 2 on the Likert scale, suggesting only a minimal element of working with the abuser on something they would have to work out together. There were no answers in the 3-5 range, with 5 indicating that it would be something that would mostly depend on the abuser's attitude and behavior. While believing that forgiveness is largely a personal process, the majority felt that the power to do this would be mostly from a higher power. With 5 being the power to forgive the abuser coming mostly from a higher power, $81.9 \%$ of those responding to the question answered with either a 4 or 5 on the scale. Only $9.1 \%$ felt that the power would come from mostly inside oneself.

There was a wide range of scores on the issue of healing and having experienced (or will experience) forgiving the abuser: $17.4 \%$ felt it was not particularly healing, $13 \%$ as slightly healing, $34.8 \%$ as somewhat healing, $17.4 \%$ as very 
Table 1. Forgiveness and Reconciliation with Abuser

\begin{tabular}{|c|c|c|c|c|c|}
\hline \multirow[b]{2}{*}{$\begin{array}{c}\text { Extend } \\
\text { abuser has been forgiven }\end{array}$} & \multicolumn{5}{|c|}{ Currently Relationship with Abuser } \\
\hline & $\begin{array}{l}\text { As much } \\
\text { distance as } \\
\text { possible }\end{array}$ & $\begin{array}{l}\text { Some distance, } \\
\text { but have } \\
\text { necessary contact }\end{array}$ & $\begin{array}{l}\text { Neither } \\
\text { avoid or } \\
\text { initiate }\end{array}$ & $\begin{array}{c}\text { Totally } \\
\text { Reconciled }\end{array}$ & Total \\
\hline Not at all & $2(8.7 \%)$ & & & & $2(8.7 \%)$ \\
\hline Having a hard time forgiving & $3(13 \%)$ & $3(13 \%)$ & $1(4.3 \%)$ & & $7(30.4 \%)$ \\
\hline In the process & $2(8.7 \%)$ & & & & $2(8.7 \%)$ \\
\hline Almost completely & & $1(4.3 \%)$ & $1(4.3 \%)$ & & $2(8.7 \%)$ \\
\hline Completely forgiven & $2(8.7 \%)$ & & $7(30.4 \%)$ & $1(4.3 \%)$ & $10(43.5 \%)$ \\
\hline Total & $9(39.1 \%)$ & $4(17.4 \%)$ & $9(39.1 \%)$ & $1(4.3 \%)$ & $23(100 \%)$ \\
\hline
\end{tabular}

Note. Numbers not adding to $100 \%$ are due to rounding issues.

healing, and $17.4 \%$ as extremely healing. In terms of the issue of true forgiveness and reconciliation, $82.6 \%$ of the subjects gave answers between reconciliation occurring none of the time and some of the time. Only 1 subject felt that true forgiveness resulted in reconciliation all of the time. Interestingly, all of the subjects answered between 1 and 3 on the Likert scale on the questions related to 'truly forgive' and the amount that you would think about the abuse, which was between never and occasionally. None of the subjects felt that if you truly forgave that you would 'frequently' or 'very often' think about the abuse.

Table 1 looks at the relationship between the extent to which the abuser has been forgiven and the current relationship with the abuser. While the subjects are in various stages of these two questions, the most interesting element is that only one person reports having completely forgiven the abuser and being totally reconciled regarding the abuse with the abuser (see Table 1). This is interesting since 11 subjects $(47.8 \%)$ indicate that their forgiveness of the abuser is a 1 (completed process) or 2 (between 'completed process' and 'currently process') on the Likert scale, suggesting a fairly strong completion of that issue, especially since 9 subjects did not answer the question (they were asked to answer this question only if they had forgiven the sexual abuser).

\section{DISCUSSION}

Of 114 subjects completing a survey on sexual abuse and forgiveness, 23 subjects indicated that they had been sexually abused (20.2\%). In the sexually abused group there were 20 females $(87 \%)$ and 3 males (13\%). This gives a sexual abuse rate of about $22 \%$ for females and $3.3 \%$ for males in the total sample. Since 88 of the subjects $(77.2 \%)$ who returned the survey were female, there is unbalanced gender representation. Since there were only 3 males their representativeness should be viewed with extreme caution.

Analysis on ethnicity was only done on how many of each group fell within the non-sexually and sexually abused groups. While numbers are small for most 
ethnic groups, and therefore analysis was not done, it is interesting to note that the largest changes in percent (comparing the non-sexually abused category to the sexually abused category) were Caucasian (a reduction of 21.3\%), Other (an increase of 12.9\%), and Asian/Pacific Islander (an increase of 9.7\%). For example, four of the eleven Asian/Pacific Islander respondents indicated that they had been sexually abused. This is a prevalence rate of $36.4 \%$ which is high compared to North American data. While the number of subjects is small in some of these categories, and one would want to be careful about generalizing these finding, further studies in this area might want to assess whether given minority groups are at higher risk for sexual abuse.

Both the non-sexually and sexually abused samples come from fairly intact families, with $84.6 \%$ and $73.9 \%$ coming from homes in which they were being raised by both parents. This may seem somewhat unusual in today's society where divorce rates are hovering around 50\% (Americans for Divorce Reform, Inc., n.d.). However, it may help account for the fact that there were no cases of step-parents sexually abusing their children, as frequently cited in the literature (Mullen \& Fleming, 1998).

As noted in the results section, those reporting sexual abuse also report higher levels of verbal and physical abuse occurring. This finding would suggest that systems in which abuse is occurring are dysfunctional in a number of ways. This study also supports the earlier reported studies on the link between sexual abuse and negative physical and emotional consequences. The sexually abused subjects reported lower levels of mental and physical health, as well as more visits to doctors and mental health professionals.

In regards to the issue of forgiveness style and sexual abuse, the data is suggestive of a disjunctive model of forgiveness. The majority of sexually abused subjects (13 out of 23) prefer to keep 'some distance' to 'as much distance as possible' from the abuser, regardless of the extent to which the abuser has been forgiven. Only one subject fit the pattern of conjunctive forgiveness. A number of subjects do not fit either model cleanly. This may be in part because in the social sciences it is unlikely that all subjects will fall into two clear cut categories (see Table 1). The above data suggests that even though there may be more than two types of forgiveness, the role of reconciliation may be unrealistic in cases of sexual abuse. The implication for individuals working with sexually abused clients, is that trying to shape their emotional experiences into a traditional reconciliation model may be inappropriate or harmful for these individuals.

There are a number of limitations to this study. There was a low return rate which could have been the result of it being totally voluntary, and the survey being of a very personal nature. The subjects were mostly from one religious denomination and this could affect their views of both sexual abuse and forgiveness. It is recommended that this study be done with larger and different samples for comparability. 


\section{REFERENCES}

Allers, C. T., Benjack, K. J., White, J., \& Rousey, J. T. (1993). HIV vulnerability and the adult survivor of childhood sexual abuse. Child Abuse and Neglect, 17, 291-298.

Americans For Divorce Reform, Inc. (n.d.). Divorce Rates: Divorce Statistics Collection. Retrieved on May 20, 2004 from http://www.divorcereform.org/rates.html

Beitchman, J. H., Zucker, K. J., Hood, J. E., daCosta, G. A., \& Akman, D. (1991). A review of the short-term effects of child sexual abuse. Child Abuse and Neglect, 15, 537-556.

Berecz, J. M. (2001). All that glitters is not gold: Bad forgiveness in counseling and preaching. Pastoral Psychology, 49, 253-275.

Berkowitz, C. D. (1998). Medical consequences of child sexual abuse. Child Abuse and Neglect, 22, 541-550.

Boney-McCoy, S., \& Finkelhor, D. (1995). Prior victimization: A risk factor for child sexual abuse and for PTSD-related symptomatology among sexually abused youth. Child Abuse and Neglect, 19, 1401-1421.

Browne, A., \& Finkelhor, D. (1986). Impact of child sexual abuse: A review of the research. Psychological Bulletin, 99, 66-77.

Chu, J. A. (1992). The revictimization of adult women with histories of childhood abuse. Journal of Psychotherapy Practice and Research, 1, 259-269.

Conte, J. R., \& Schuerman, J. R. (1987). Factors assoiciated with an increased impact of child sexual abuse. Child Abuse and Neglect, 11, 201-211.

Enright, R. L. (2000). Helping clients forgive: An empirical guide for resolving anger and restoring hope. Washington, DC: American Psychological Association.

Feehan, M., Nada-Raja, S., Martin, J. A., \& Langley, J. D. (2001). The prevalence and correlates of psychological distress following physical and sexual assault in a young adult cohort. Violence and Victims Special Issue, 16, 49-63.

Finestone, H. M., Stenn, P., Davies, F., Stalker, C., Fry, R., \& Koumanis, J. (2000). Chronic pain and health care utilization in women with a history of childhood sexual abuse. Child Abuse and Neglect, 24, 547-556.

Finkelhor, D. (1979). Sexually victimized children and their families. Dissertations Abstracts International, 39, 7006-7007.

Finkelhor, D., Hotaling, G. T., Lewis, I. A., \& Smith, C. (1989). Sexual abuse and its relationship to later sexual satisfaction, marital status, religion, and attitudes. Journal of Interpersonal Violence, 4, 379-399.

Finkelhor, D., Hotaling, G., Lewis, I., \& Smith, C. (1990). Sexual abuse in a national survey of adult men and women: Prevalence, characteristics, and risk factors. Child Abuse and Neglect, 14, 19-28.

Freedman, S. R., \& Enright, R. D. (1996). Forgiveness as an intervention goal with incest survivors. Journal of Consulting and Clinical Psychology, 64, 983-993.

Gidycz, C. A., Coble, C. N., Latham, L., \& Layman, M. J. (1993). Sexual assault experience in adulthood and prior victimization experiences: A prospective analysis. Psychology of Women Quaterly, 17, 151-168.

Gorey, K. M., \& Leslie, D. R. (1997). The prevalence of child sexual abuse: Integrative review adjustment for potential response and measurement biases. Child Abuse and Neglect, 21, 391398.

Haugaard, J. (2000). The challenge of defining child sexual abuse. American Psychologist, 55, 10361039.

Hebel, J., \& Enright, R. D. (1993). Forgiveness as a psychotherapeutic goal with elderly females. Psychotherapy, 30, 658-667.

Holmes, W. C., \& Slap, G. B. (1998). Sexual abuse of boys: Definition, prevalence, correlates, sequelae, and management. Journal of the American Medical Association, 280, 1855-1862.

Jackson, J. L., Calhoun, K. S., Amick, A. E., Maddever, H. M., \& Habif, V. L. (1990). Young adult women who report childhood intrafamilial sexual abuse: Subsequent adjustment. Archieves of Sexual Behavior, 19, 211-221.

Jantzen, K., Ball, S. A., Leventhal, J. M., \& Schottenfeld, R. S. (1998). Type of abuse and cocaine use in pregnant women. Journal of Substance Abuse Treatment, 15, 319-323. 
Kendall-Tackett, K. A., Williams, L. M., \& Finkelhor, D. (1993). Impact of sexual abuse on children: A review and synthesis of recent empirical studies. Psychological Bulletin, 113, 164-180.

Kendler, K. S., Bulik, C. M., Silberg, J., Hettema, J. M., Myers, J., \& Prescott, C. A. (2000). Childhood sexual abuse and adult psychiatric and substance use disorders in women: An epidemiological and cotwin control analysis. Archieves of Epidemiology, 6, 357-364.

Kenny, M. C., \& McEachern, A. G. (2000). Prevalence and characteristics of childhood sexual abuse in multiethnic female college students. Journal of Child Sexual Abuse Special Issue, 9, 57-70.

Konstam, V., Marx, F., Schurer, J., Harrington, A., Lombardo, N. E., \& Deveney, S. (2000). Forgiving: What mental health counselors are telling us. Journal of Mental Health Counseling, 22, 253-268.

Madu, S. N., \& Peltzer, K. (2001). Prevalence and patterns of child sexual abuse and victim-perpetrator relationship among secondary school students in the Northern Province (South Africa). Archives of Sexual Behavior Special Issue, 30, 311-321.

Mayall, A., \& Gold, S. R. (1995). Definitional issues and mediating variables in the sexual revictimization of women sexually abused as children. Journal of Interpersonal Violence, 10, $26-42$.

Messman, T. L., \& Long, P. J. (1996). Child sexual abuse and its relationship to revictimization in adult women: A review. Clinical Psychology Review, 16, 397-420.

Molnar, B. E., Buka, S. L., \& Kessler, R. C. (2001). Child sexual abuse and subsequent psychopathology: Results from the National Comorbidity Survey. American Journal of Public Helath, 91 , 753-760.

Mullen, P. E., \& Fleming, J. (1998). Long-term effects of child sexual abuse. Issues in Child Abuse Prevention, 9. Retrieved from http://www.aifs.org.au/nch/issues $9 . h t m l$

National Right To Life. (1999, March 24). Key points on child custody protection act. Retrieved on May 19, 2004, from http://www.nrlc.org/Federal/CCPA/key_point_CCPA.htm

Oaksford, K. L., \& Frude, N. (2001). The prevalence and nature of child sexual abuse: Evidence from a female university sample in the UK. Child Abuse Review Special Issue, 10, 49-59.

Paolucci, E. O., Genuis, M. L., \& Violato, C. (2001). A meta-analysis of the published research on the effects of child sexual abuse. Journal of Psychology, 135, 17-36.

Rind, B., Tromovitch, P., \& Bauserman, R. (1998). A meta-analytic examination of assumed properties of child sexual abuse using college samples. Psychological Bulletin, 124, 22-53.

Romero, G. J., Wyatt, G. E., Loeb, T. B., Carmona, J. V., \& Solis, B. M. (1999). Prevalence and circumstances of child sexual abuse among Latina women. Hispanic Journal of Behavioral Sciences Special Issue, 21, 351-365.

Siegel, J. M., Sorenson, S. B., Golding, J. M., Burnam, M. A., \& Stein, J. A. (1987). The prevalence of childhood sexual assault: The Los Angeles Epidemiological Catchment Area Project. American Journal of Epidemiology, 126, 1141-1153.

Subkoviak, M. J., Enright, R. D., Wu, C., \& Gassin, E. A. (1995). Measuring interpersonal forgiveness in late adolescence and middle adulthood. Journal of Adolescence, 18, 641-655.

Thompson, N. J., Potter, J. S., Sanderson, C. A., \& Maibach, E. W. (1997). The relationship of sexual abuse and HIV risk behaviors among heterosexual adult female STD patients. Child Abuse and Neglect, 21, 149-156.

University of Michigan, Sexual Assault Prevention and Awareness Center. (n.d.). Michigan Criminal Sexual Conduct (CSC) Laws. Retrieved on May 20, 2004, from http://www.umich.edu/ $\sim$ sapac/csc.html

Vogeltanz-Holm, N. D. (2002). Childhood sexual abuse and risk for psychopathology. In N. J. Smelser \& P. B. Baltes (Eds.), International encyclopedia of the social and behavior sciences, Vol. 3 (pp. 1712-1716). London: Elsevier Science.

Wakefield, H., Rogers, M., \& Underwager, R. (1990). Female sexual abusers: A theory of loss. Issues in Child Abuse Accusations, 2, 181-195.

Wingood, G. M., \& DiClemente, R. J. (1997). Child sexual abuse, HIV sexual risk, and gender relations of African-American women. American Journal of Preventative Medicine, 13, 380-384.

Wyatt, G. E., Guthrie, D., \& Notgrass, C. M. (1992). Differential effects of women's child sexual abuse and subsequent sexual revictimization. Journal of Consulting and Clinical Psychology, 60, $167-173$.

Wyatt, G. E., Loeb, T. B., Solis, B. M., Carmona, J. V., \& Romero, G. J. (1999). The prevalence and circumstances of child sexual abuse: Changes across a decade. Child Abuse and Neglect, 23, 45-60. 